\title{
Blast-resistant highway bridges: design and detailing guidelines
}

\author{
G. Williams ${ }^{1}$, C. Holland ${ }^{1}$, E. Williamson ${ }^{1}$, O. Bayrak ${ }^{1}$, \\ K. Marchand ${ }^{2}$ \& J. Ray ${ }^{3}$ \\ ${ }^{1}$ Department of Civil, Architectural, and Environmental Engineering, \\ University of Texas at Austin, USA \\ ${ }^{2}$ Protection Engineering Consultants, USA \\ ${ }^{3}$ U.S. Army Corps of Engineers, \\ Engineer Research and Development Center, USA
}

\begin{abstract}
The design of bridges to resist blast loads has become an international concern in recent years. Data from the U.S. State Department indicate that violent attacks against transportation targets have increased worldwide over the last decade and that highway infrastructure has been the most frequently attacked transportation target. Since September $11^{\text {th }}$, 2001, increased emphasis on bridge security has raised awareness in the engineering community that bridges and other transportation structures should be designed to better respond to potential terrorist attacks. The fact that many bridges provide open access, carry thousands of motorists, and may have symbolic importance makes them attractive targets, and the success of recent terrorist bombings on bridges during the ongoing "war on terror" highlight the vulnerability of these structures. This paper presents preliminary results and observations from blast tests on concrete bridge columns conducted during a U.S. national study to develop design and detail guidelines for blast-resistant highway bridges.
\end{abstract}

Keywords: blast, bridge, column, concrete, explosive, terrorism.

\section{Introduction}

Structural engineers have the responsibility of designing strong, durable structures that are able to resist extreme loading scenarios without collapsing. Past research on blast-resistant designs focused primarily on buildings, but the 
attention of the structural engineering community is now turning to highway bridges. Although ordinary highway bridges may not seem like probable terrorist targets, historical evidence suggests otherwise. A confiscated Al Qaeda training manual states that terrorist goals include "destroying and blasting bridges leading into and out of the city" in order to "strike terror [into the hearts] of the enemies" [1]. The success of recent attacks on overpass bridges in Iraq illustrates the realization of these goals, and historical data confirm that terrorists' desire to attack ordinary bridges spans many years. A report from the Mineta transportation institute [2] indicates that 53 terrorist attacks specifically targeted bridges between 1980 and 2006, and 58\% of bridges targeted worldwide and $35 \%$ of bridges targeted in industrialized nations during that time were highway bridges other than signature bridges. Considering that $60 \%$ of all attacks on transportation targets during that time were bombings, a bombing of an ordinary highway bridge is a realistic scenario, and structural engineers need recommendations for blast-resistant bridge design. This paper presents preliminary observations from experimental research on blast-loaded bridge columns, and it outlines ongoing analytical work to develop design guidelines for blast-resistant bridges.

\section{Test method}

Highway bridges can vary significantly in size and configuration, and each has many structural members that contribute to the global response of the structure. Although many bridge types and structural components deserve attention, establishing the behavior of blast-loaded bridge columns will provide the greatest current contribution to the bridge community as a whole. Bridge columns are essential to nearly all bridges and bridge types, and they are arguably the most important structural element in a bridge. Many bents have only one column, which means failure of a single column could initiate collapse of an entire bridge. Elevated interstate highway interchanges with single column bents are especially vulnerable, and the collapse of the highest superstructure in one of these systems may mean failure of all those below. Additionally, bridge columns typically offer unrestricted access to the public, making them attractive targets for potential attackers. Thus, understanding their response to blast loads is essential, and this research investigates the influence of splice location, crosssection shape and size, and transverse reinforcement type and spacing on the behavior of blast-loaded bridge columns.

\subsection{Specimens}

Individual state departments of transportation (DOTs) govern bridge construction throughout the United States. As a result, design preferences can vary within the national bridge community, and the results of this research are intended to benefit a broad range of design practices. Although standards do vary throughout the nation, consultations with state DOT design guidelines and representatives show that general trends do exist, and the specimens in this study represent the most commonly used bridge column design parameters. 
Table 1: Design parameters for concrete bridge column specimens.

\begin{tabular}{|c|ccccc|}
\hline $\begin{array}{c}\text { Column } \\
\text { Label }\end{array}$ & Shape & $\begin{array}{c}\text { Diameter } \\
\mathrm{ft}(\mathrm{m})\end{array}$ & $\begin{array}{c}\text { Longitudinal } \\
\text { Reinforcement } \\
\text { Ratio }\end{array}$ & $\begin{array}{c}\text { Transverse } \\
\text { Steel Type }\end{array}$ & $\begin{array}{c}\text { Transverse } \\
\text { Steel } \\
\text { Design }\end{array}$ \\
\hline 1A1 & Circular & $1.5(0.46)$ & 1.04 & Hoops & Typical \\
1A2 & Circular & $1.5(0.46)$ & 1.04 & Hoops & Typical \\
1B & Circular & $1.5(0.46)$ & 1.04 & Spiral & Typical \\
2A1 & Circular & $2.5(0.76)$ & 1.13 & Hoops & Typical \\
2A2 & Circular & $2.5(0.76)$ & 1.13 & Hoops & Typical \\
2B & Circular & $2.5(0.76)$ & 1.13 & Spiral & Typical \\
2-seismic & Circular & $2.5(0.76)$ & 1.13 & Spiral & Seismic \\
2-blast & Circular & $2.5(0.76)$ & 1.13 & Spiral & Blast \\
3A & Square & $2.5(0.76)$ & 1.18 & Ties & Typical \\
3-blast & Square & $2.5(0.76)$ & 1.18 & Ties & Blast \\
\hline
\end{tabular}

The testing program contains 10 half-scale specimens, and Table 1 presents selected details of each specimen. The research plan emphasizes circular crosssections because they are the most common cross-section used today in U.S. transportation infrastructure. The half-scale specimens include three $1.5-\mathrm{ft}$ (0.46-m) diameter round columns, five $2.5-\mathrm{ft}(0.76-\mathrm{m})$ diameter round columns, and two square columns with edge widths of $2.5 \mathrm{ft}(0.76 \mathrm{~m})$. All specimens have a total height of $11.25 \mathrm{ft}(3.43 \mathrm{~m})$. Five circular columns and one square column employ typical DOT designs. The longitudinal reinforcement ratios of these specimens remain constant for all cross-section sizes and shapes, while the transverse reinforcement varies to study its influence on performance. All longitudinal reinforcement in the columns have splices near the base using conventional construction detailing, except columns $2 \mathrm{~B}$ and 2-seismic, which have no rebar splices, to examine the effect of splice location on column response. The design of one column was based on seismic standards to investigate the influence of larger transverse reinforcement ratios, and two columns are special blast-resistant columns designed specifically for this study with significant increases in the transverse reinforcement volumetric ratio.

\subsection{Boundary conditions and reaction structure}

The boundary conditions selected for these blast tests are those of a propped cantilever, which are a fixed condition at the base of the column and a pinned condition at the top. These boundary conditions model a scenario in which the location of an explosion is directly beneath the deck and directly to the side of a column. Thus, the pinned condition at the top of the specimens models the superstructure, which is essentially axially stiff along its primary axis, and the fixed condition at the base of the specimens models the column foundation. The axial loads experienced by bridge columns in service typically do not exceed the balance point of the column, and any applied axial load only improves the response. Thus, testing specimens as propped-cantilevers with no applied axial load is conservative and logistically desirable. 
A specially constructed reaction structure provides the desired boundary conditions. This reaction structure consists of a steel frame of 8 -in $\times 8$-in $\times$ 0.625 -in $(20.3-\mathrm{cm} \times 20.3-\mathrm{cm} \times 1.59-\mathrm{cm})$, A500 Grade B structural steel tubes cast in a $29-\mathrm{ft} \times 14-\mathrm{ft}(8.84-\mathrm{m} \times 4.27-\mathrm{m})$ reinforced concrete slab. The steel frame provides the pinned connection at the top of the specimens, and the concrete slab provides the fixed boundary condition at the base of the specimens. Figure 1 shows a schematic of the reaction structure and column, and Figure 2 shows a picture of the reaction structure with a specimen prior to testing.

The slab is predominantly $2-\mathrm{ft}(0.61-\mathrm{m})$ thick, but the section of slab nearest the explosion where the column foundations rest is $2.5-\mathrm{ft}(0.76-\mathrm{m})$ deep. This front section has a $5-\mathrm{ft}, 2.5$-in $(1.59-\mathrm{m}) \times 7-\mathrm{ft}(2.13-\mathrm{m})$ cavity in which the columns rest. Each column sits on a $2.5-\mathrm{ft} \times 2.5-\mathrm{ft} \times 5.0-\mathrm{ft}(0.76-\mathrm{m} \times 0.76-\mathrm{m} \times$ $1.52-\mathrm{m})$ foundation that fits into this cavity, and high-strength, quick-set grout fills the gaps in the front and the back of the cavity to provide the fixed restraint. The cavity also has room on each side of the column foundations for instrumentation wires to exit the foundations and connect with cables connected to the high-speed data acquisition system.

\subsection{Blast tests}

The construction of the specimens began in August 2007 and finished in September 2007, and testing commenced in early October 2007 and extended

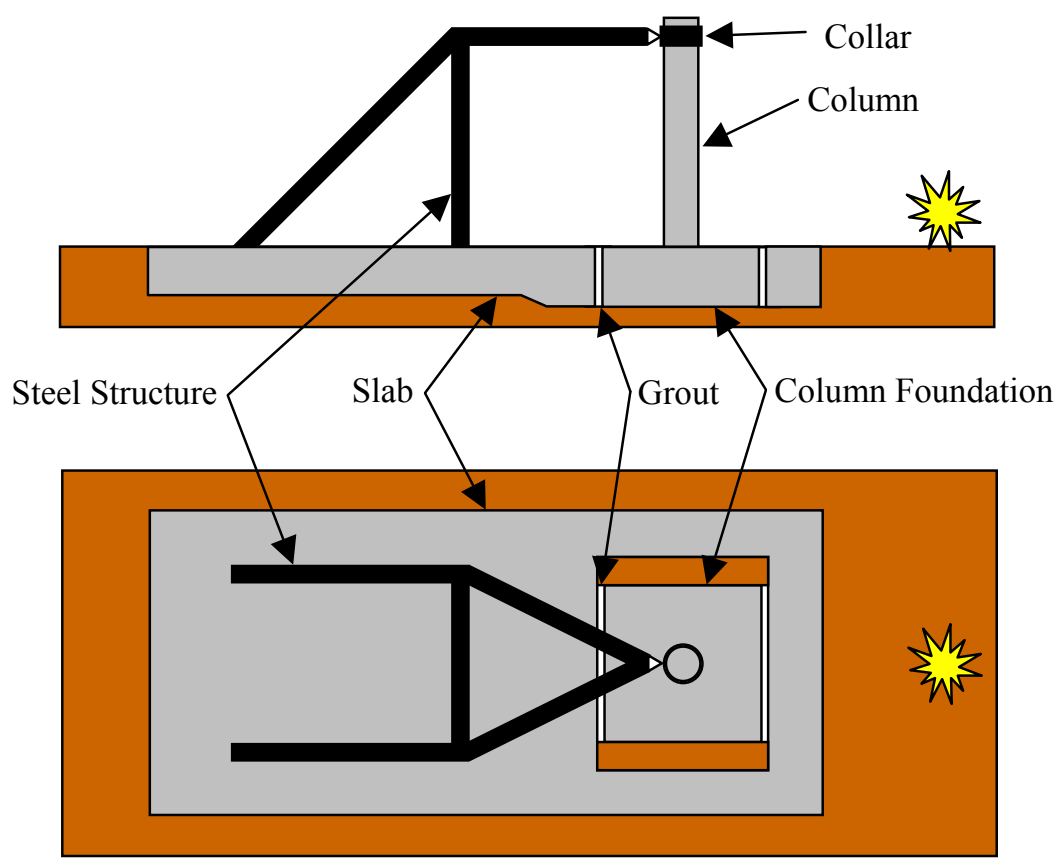

Figure 1: $\quad$ Schematic of reaction structure and test setup. 


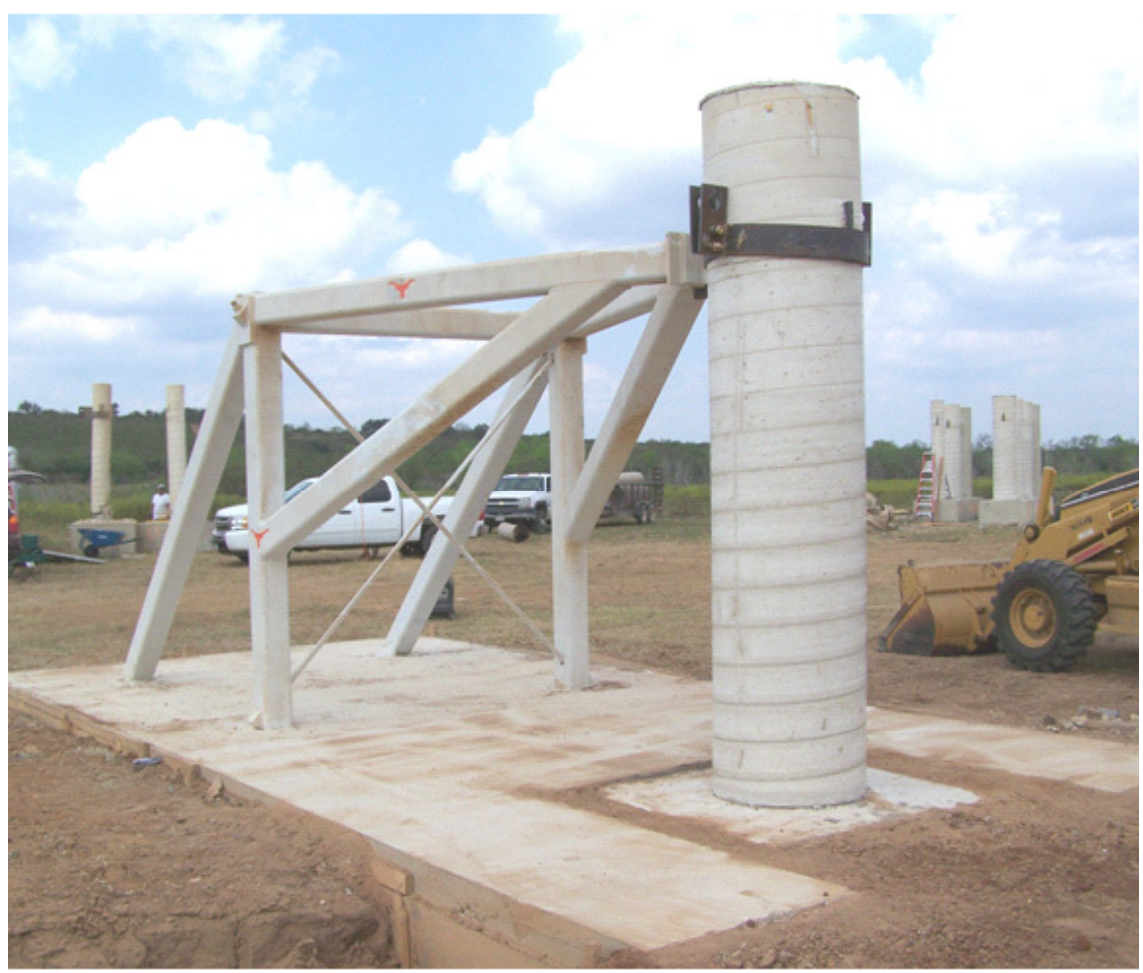

Figure 2: $\quad$ Picture of reaction structure and column before the test.

over a 16-day period. As previously mentioned, the column foundations lowered into the cavity in the front of the slab. Grout placed between the front and back faces of the column foundations and the reaction slab provided the fixed conditions at the base, and a steel clamp attached to the top of the columns that bolted to the steel reaction frame supplied the pinned restraint at the top of the columns. This method of connecting the column to the reaction structure provided the desired boundary conditions, while allowing for quick column removal and replacement.

Testing of the columns was divided into two different series. The intent of the first test series was to evaluate the overall performance of each column design. For this purpose, the charge weights and standoff distances were selected to avoid significant spall and breach damage, while identifying the dominant mode of response - whether shear, flexure, or a combination of both for the set of design parameters used in each column. Afterwards, a second test series examined the spall and breach capacities of selected specimens. The columns selected for these additional tests had minor flexural or shear cracking only, and thus the damage existing prior to these tests did not greatly influence the results. In both test series, ANFO was used for the explosive charges; this paper does not disclose the exact charge weights and standoff distances for security purposes. 
Three pressure gages recorded overpressures at $37 \mathrm{ft}(11.3 \mathrm{~m}), 52 \mathrm{ft}(15.9 \mathrm{~m})$, and $76 \mathrm{ft}(23.2 \mathrm{~m})$ away from the charge, and each test yielded 6 channels of strain data for the reinforcing steel. The two specimens with no splices had three strain gages on the transverse steel and three strain gages on the back-face flexural steel (i.e., tension reinforcement for initial response), and the eight specimens with longitudinal reinforcement splices had two strain gages each above and below the splice on the back-face longitudinal steel (i.e., four total gages on the longitudinal reinforcement) and two strain gages on the transverse reinforcement near the base of the column. High-speed cameras visually captured the response, and after each test, the field team inspected the specimen, identified and recorded damage, marked and sketched crack patterns, and thoroughly photographed all observations.

\section{Initial observations and results}

The visual and recorded data show the dominant modes of response for a given set of column parameters, charge weight, and standoff distance. Several initial observations illustrate general trends in performance related to a column's section properties, and additional analysis will provide detailed recommendations for bridge column design. This paper cannot describe the performance of each column in great detail due to security concerns, and it only provides an overview of basic observations.

\subsection{Shear and flexure tests}

Prior to testing, shear at the column base (both direct and sectional) was anticipated to control the performance of the blast-loaded columns. Although the principle response modes varied depending on section properties, charge weight, and standoff distance, base shear did clearly dominate the response in most cases. Extensive shear cracking patterns were evident in most specimens, and these specimens showed little to no flexural cracking. A few tests with larger charge weights or smaller standoff distances resulted in extensive shear damage at the base of the column. Figure 3 shows extensive shear damage at the base of one of the specimens. As planned, these specimens experienced essentially no spall or breach damage during the initial shear and flexure tests.

The scaled standoff distances forced a few specimens to complete shear failure, but some columns appeared to retain load-carrying capacity. Although direct shear dominated the response in most cases, specimens with adequate shear capacity performed very well and exhibited clear cracking patterns indicative of combined flexural and shear behavior. Figure 4 shows flexural cracking on the back face (i.e., tension side for initial response) of a specimen.

Overall, the half-scale bridge columns performed more robustly than expected. Trial specimens tested to establish appropriate scaled standoffs had only superficial damage, and the blast intensities of subsequent tests had to be increased to obtain desired levels of damage. This observation shows that bridge 
columns may have greater capacity than previously thought; however, a few design parameters can change to improve response, two of which include increasing the volumetric transverse steel ratio and eliminating longitudinal reinforcement splices in vulnerable regions. Furthermore, cross-sections with continuous (i.e., spiral) shear reinforcement performed better than columns reinforced with the same percentage of steel using hoops.

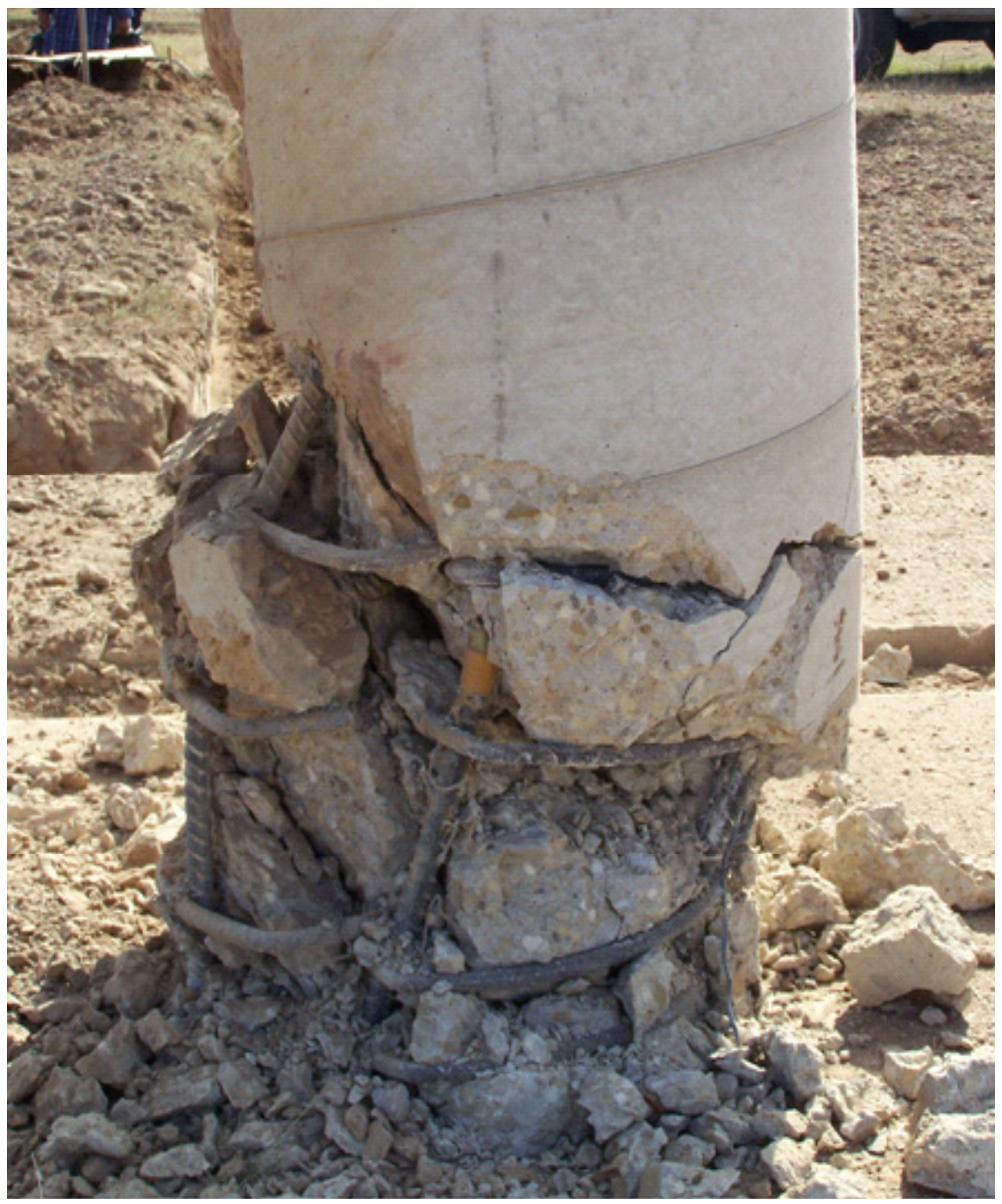

Figure 3: Extensive shear damage at the base of the specimen. 


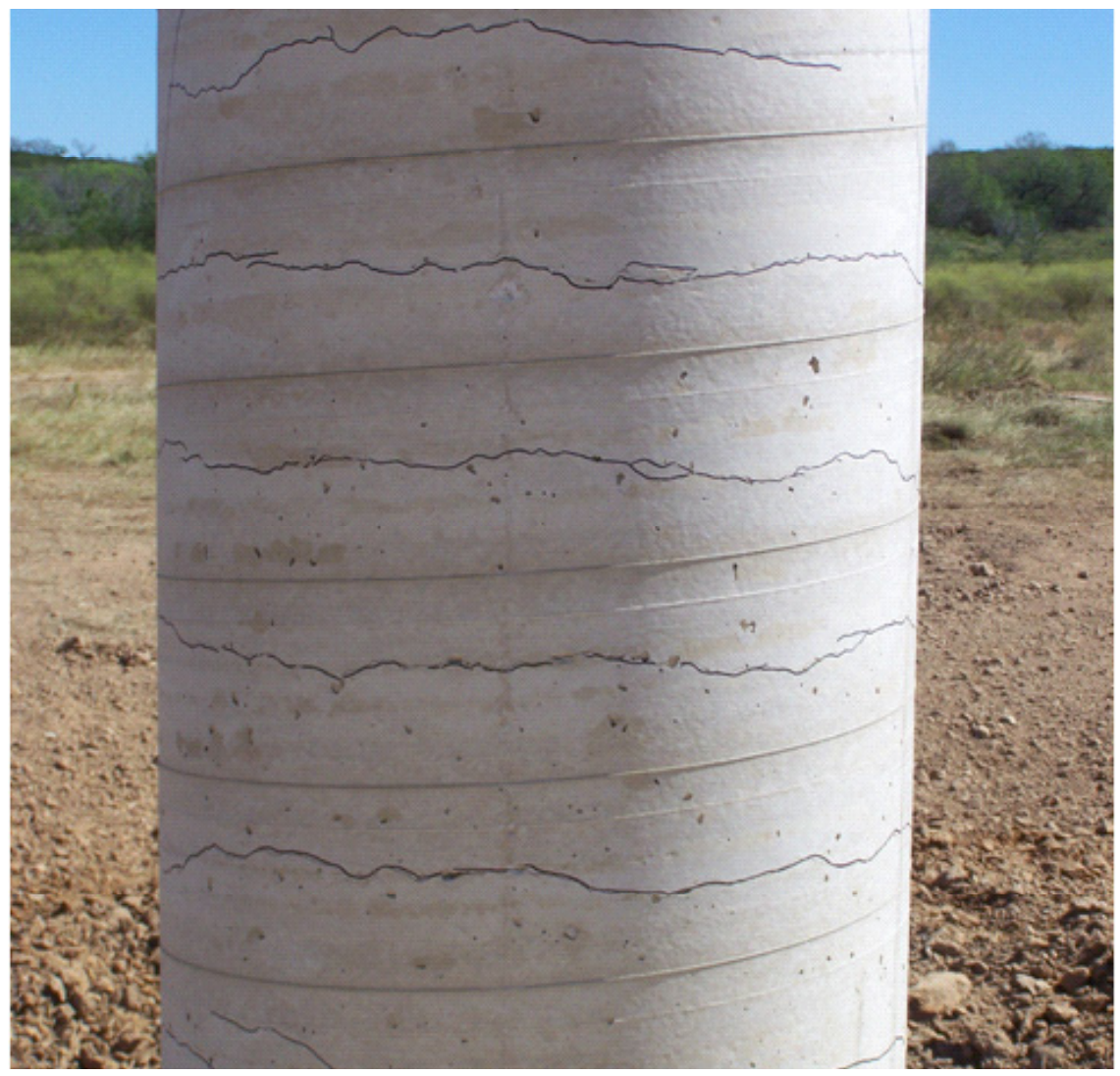

Figure 4: Flexural cracking on the back face of the specimen.

\subsection{Spall and breach tests}

As previously mentioned, additional tests examined the spall and breach capacities of six columns. The specimens used for these tests sustained only light damage during the first series of shear and flexure tests, and the minor cracking damage present before the second series of tests did not significantly affect the results. Initial observations indicate that current methods available to predict spall and breach of concrete walls do not apply to columns. Due to security restrictions, this paper cannot provide additional information about these tests.

\section{Future work}

The information obtained during these 16 blast tests provides a valuable foundation on which to build blast-resistant bridge columns, and analytical parameter studies will further contribute to the understanding of how selected design parameters influence column response. To that end, the strain gage data and visual records from the experimental blast tests described in this paper will 
permit the calibration of 3D nonlinear, finite element analyses in LS-DYNA [3] that will study the influence of cross-section shape and size, longitudinal reinforcement bar size and ratio, and transverse steel bar size and spacing on bridge column response to blast loads. The combined results of the experimental tests and the analytical parameter study will help establish design recommendations for blast-resistant bridge columns and help calibrate singledegree-of-freedom analysis tools for design office use.

\section{Acknowledgements}

The authors would like to thank the professors and graduate students of the University of Texas at Austin, United States for their instruction, time, and dedication to this research; Protection Engineering Consultants in Texas, United States for the successful design and management of the blast tests; the Southwest Research Institute in Texas, United States for their field work and expertise in explosive engineering; and the National Cooperative Highway Research Program (NCHRP) of the United States for the funds needed to conduct this research. The information contained in this paper reflects the opinions of the authors and not necessarily those of the sponsor.

\section{References}

[1] Military Studies in the Jihad Against the Tyrants, Al Qaeda Terrorist Training Manual captured in Manchester, England; United States Department of Justice (USDJ) Online.

[2] http://www.usdoj.gov/

[3] Jenkins, B.M., \& Gersten, L.N., Protecting Public Surface Transportation against Terrorism \& Serious Crime, Mineta Transportation Institute: San Jose, California, 2001.

[4] Livermore Software Technology Corporation (LSTC), LS-DYNA Keyword User's Manual, Version 971, Livermore Software Technology Corporation: Livermore, California 2007. 